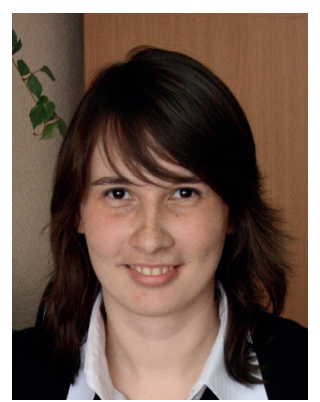

Мухамадиева Э. Ф.

Mukhamadieva E. F.

кандидат экономических наук,

дочент кафедры «Экономическая

безопасность» Инстититута экономики

и сервиса, ФГБОУ ВО «Уфимский

государственный нефтяной технический университет»,

2. Уфа, Российская Федерация

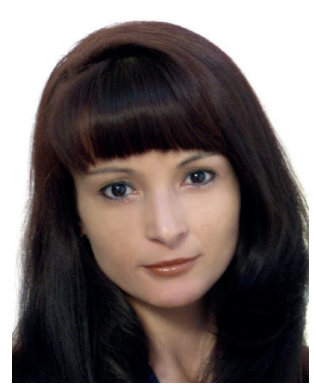

Кашипова И. Р. Kashipova I. $R$.

кандидат экономических наук, доиент, заместитель директора,

Уфимский филиал ФГОБУ ВО «Финансовый университет при Правительстве

Российской Федераичии,,

2. Уфа, Российская Федеращия

DOI: $10.17122 / 2541-8904-2019-2-28-36-42$

УДК 336.7 (470)

И ТЕНДЕНЦИИ РАЗВИТИЯ РЫНКА МИКРОФИНАНСОВЫХ УСЛУГ В РОССИИ

В статье проводится анализ современного состояния рынка микрофинансовых услуг в России как наиболее динамично развивающегося сектора финансового рынка России. Представлены официальные статистические данные, отражающие различные аспекты деятельности рынка микрофинансовых услуг, в том числе дана количественная характеристика институционального развития рынка микрофинансовых услуг России; проведена оценка динамики объема портфеля займов микрофинансовых институтов; исследована структура совокупного портфеля микрозаймов в разрезе основных категорий потребителей микрофинансовых услуг и т.д. По итогам проведенного анализа определены тенденции развития рынка микрофинансовых услуг, а также выявлены проблемы, существенно сдерживающие уровень их дальнейшего развития. Так, к числу факторов, сдерживающих эффективное развитие рынка микрофинансовых услуг, отнесены: низкий уровень финансовой грамотности потребителей микрофинансовых услуг; отсутствие системы обязательного страхования займов; отсутствие залоговой базы у микрофинансовых организаций; высокие процентные ставки размещения займов, зачастую обусловленные отсутствием долгосрочных и дешевых источников фондирования; недостаточный объем финансовых ресурсов, находящихся в распоряжении микрофинансовых организаций, не способных удовлетворить потенциальный спрос на микрофинансовые услуги; неразвитость системы управления рисками; присутствие «теневого сектора» на рынке микрофинансовых услуг; недостаточная проработанность действующего законодательства, регламентирующего деятельность рынка микрофинансовых услуг; отсутствие унифицированных форм отчетности микрофинансовых организаций, позволяющих получить объективную оценку их деятельности и отвечающих требованиям мировых стандартов; отсутствие единообразных показателей, характеризующих финансовую устойчивость микрофинансовых организаций; практическое отсутствие государственной поддержки рынка микрофинансовых услуг; отсутствие единых стандартов реструктуризации и рефинансирования займов; отсутствие утвержденных рейтинговых оценок микрофинансовых организаций; отсутствие механизма выявления и пресечения злоупотреблений в сфере микрофинансовой деятельности и другие. При этом перспективы развития микрофинансовых институтов, на взгляд авторов, будут напрямую зависеть от эффективного решения выше обозначенных проблем.

Ключевые слова: микрофинансирование, микрофинансовые организации, рынок микрофинансовых услуг, микрофинансовые институты, кредитные потребительские 
кооперативы, сельскохозяйственные кредитные потребительские кооперативы, жилищные накопительные кооперативы, бюро кредитных исследований, институциональное развитие.

\section{MODERN CONDITION AND DEVELOPMENT TRENDS OF MICROFINANCE SERVICES MARKET IN RUSSIA}

The article analyzes the current microfinance services market state in Russia, as the most dynamically developing sector of the Russian financial market. The official statistics are presented, reflecting microfinance services market various aspects, including a quantitative description of the institutional development of the microfinance services market in Russia; the dynamics of microfinance institutions loan portfolio volume was assessed; investigated the total microloan portfolio structure in the context of the microfinance services consumers main categories, etc. According to the analysis results, trends in the microfinance services market development were identified, and problems that significantly restrain the their further development level were identified. So, among the factors constraining the microfinance services market effective development are: low level of financial literacy of microfinance consumers; lack of a compulsory loan insurance system; lack of microfinance organizations collateral base; high interest rates for placing loans, often due to the lack of long-term and cheap sources of funding; insufficient financial resources amount held by microfinance organizations that are not able to meet the potential demand for microfinance services; undeveloped risk management system; the «shadow sector» presence in the microfinance services market; insufficient elaboration of the current legislation regulating the microfinance services market activities; the lack of standardized reporting forms for microfinance organizations that provide an objective assessment of their activities and meet the requirements of world standards; the lack of uniform indicators characterizing the microfinance organizations financial sustainability; the state support absence for the microfinance market; the lack of uniform standards for restructuring and refinancing loans; lack of approved rating microfinance organizations assessments; the mechanism absence for identifying and preventing abuses in the field of microfinance and others. At the same time, the prospects for microfinance institutions development, in the opinion of the authors, will directly depend on the effective solution of the above problems.

Key words: microfinance, microfinance organizations, microfinance services market, microfinance institutions, consumer credit cooperatives, agricultural consumer credit cooperatives, housing savings cooperatives, credit research bureaus, institutional development.

Микрофинансовые организации (МФО), наращивая объемы и расширяя масштабы своей деятельности, продолжают приобретать все большую популярность, выступая наиболее динамично развивающимся сектором финансового рынка России. Вместе с тем, официальные статистические данные, представленные в таблице 1, отражают общую тенденцию сокращения числа микрофинансовых институтов (МФИ). Снижение числа организаций, по-прежнему, в основном связано с усилением надзора Банка России, что приводит к очищению рынка от недобросовестных участников [1]. Так, например, за последние 5 лет, число микрофинансовых организаций в России сократилось более чем в 2 раза (с 4200 ед. в 2014 г. и 2001 МФО - по итогам 3 квартала 2018 г.), количество кредитных потребительских кооперативов уменьшилось более чем на треть (с 3545 до 2361). Вместе с тем, следует отметить, что по сведениям Банка России рынок покинули преимущественно слабые игроки, сокращение числа компаний, внесенных в реестр МФО, не оказало влияния на развитие сегмента в целом.

По данным Национального бюро кредитных исследований (НБКИ) по состоянию на 01.04.2018 суммарный объем предоставленных МФИ (МФО, КПК и т.д.) займов населению составил 181,2 млрд руб., увеличившись за 1 квартал 2018 г. на 10,0\% (на 01.01.2018 - 164,7 млрд руб.) (рисунок 1) [2].

Микрофинансовые организации на рынке микрофинансовых услуг занимают третье место по уровню институционального развития. Если же рассматривать данные, характеризующие динамику заключенных договоров микрозайма, то можно отметить тенденцию ежегодного прироста спроса на 
Таблица 1. Количественная характеристика институционального развития рынка микрофинансовых услуг России, ед.

\begin{tabular}{|c|c|c|c|c|c|c|}
\hline № ח/П & Микрфинансовые институты & 2014 г. & 2015 г. & 2016 г. & 2017 г. & 2018 г. \\
\hline 1 & Кредитные потребительские кооперативы (КПК) & 3545 & 3500 & 3059 & 2666 & 2476 \\
\hline 2 & $\begin{array}{l}\text { Сельскохозяйственные кредитные потребительские } \\
\text { кооперативы (СКПК) }\end{array}$ & н/д & 1738 & 1470 & 1242 & 1146 \\
\hline 3 & Ломбарды & н/д & 8417 & 7415 & 5782 & 5276 \\
\hline 4 & Микрофинансовые организации (МФО) & 4200 & 3688 & 2588 & 2271 & 2124 \\
\hline 5 & Жилищные накопительные кооперативы (ЖНК) & 88 & 77 & 69 & 63 & 60 \\
\hline
\end{tabular}

Ежеквартальный прирост портфеля займов МФИ, в \%

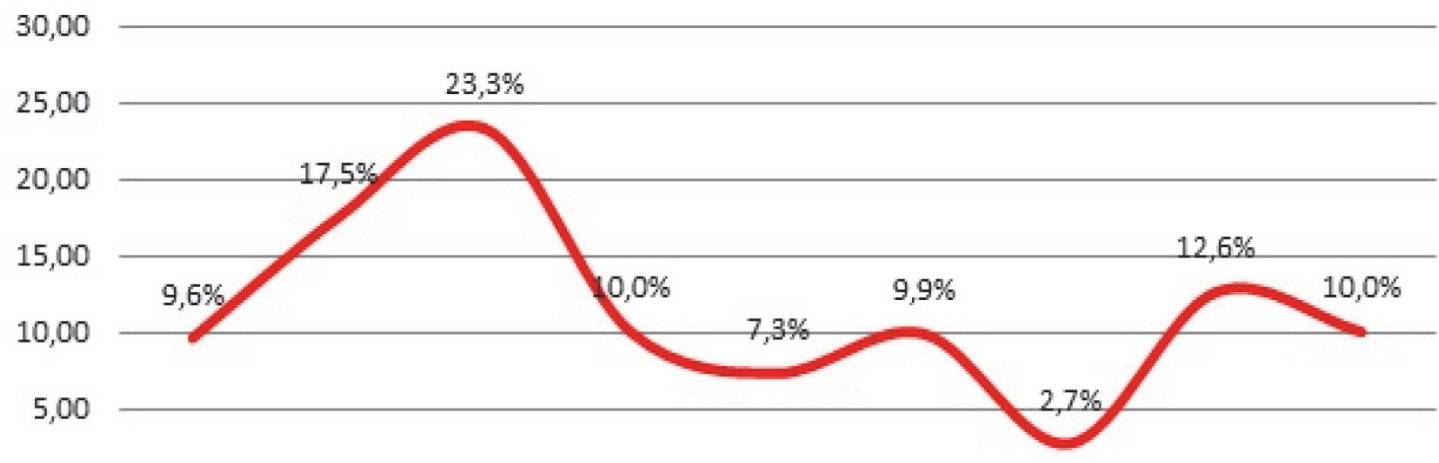

0,00

1 кв. 20162 кв. 20163 кв. 20164 кв. 20161 кв. 20172 кв. 20173 кв. 20174 кв. 20171 кв. 2018

Рисунок 1. Динамика объема портфеля займов МФИ в 2016-2018 гг., в \% Источник: НБКИ https://www.nbki.ru/press/pressrelease/?id=21700

микрозаймы - среднегодовой прирост за 2014-2017 гг. составил по России 37,13\% [3]. При этом следует обратить внимание на то, что максимальный прирост спроса наблюдался в 2016 г. - темп прироста по количеству заключенных договоров микрозайма по России составил 67,98 \% по сравнению с пре- дыдущим периодом. Также особого внимания заслуживает динамика спроса на услуги предоставления микрозаймов с использованием дистанционных технологий (онлайн микрозаймы), которые по итогам 2017 г. возросли почти вдвое (таблица 2) [4].

Таблица 2. Количество договоров микрозайма МФО, заключенных за отчетный период

\begin{tabular}{|c|c|c|c|c|c|c|}
\hline № П/П & Наименование показателя & 2014 г. & 2015 г. & 2016 г. & 2017 г. & 2018 г. \\
\hline \multirow{2}{*}{1} & Всего договоров микрозайма, тыс. ед. & \multirow{2}{*}{8712,9} & \multirow{2}{*}{11320,3} & \multirow{2}{*}{19015,1} & \multirow{2}{*}{23498,9} & \multirow{2}{*}{21245,2} \\
\hline & в том числе в разрезе заемщиков: & & & & & \\
\hline 1.1 & индивидуальные предприниматели & 45,8 & 32,2 & 25,3 & 14,4 & 9,8 \\
\hline 1.2 & юридические лица & 33,9 & 21,4 & 19,4 & 20,7 & 12,5 \\
\hline 1.3 & физические лица & 8633,2 & 11266,7 & 18970,4 & 23463,8 & 21222,9 \\
\hline 2 & онлайн микрозаймы, ед. & $\mathrm{H} / д$ & Н/д & 3663 & 6721,2 & 8759 \\
\hline
\end{tabular}

Представленные данные также позволяют увидеть, что в структуре заключенных договоров микрозайма доминирующая часть приходится на физических лиц $(99,9 \%)$. При этом в поквартальном разрезе структура потребителей микрофинансовых услуг
МФО особых изменений не претерпевает (таблица 3).

При сложившейся тенденции сокращения количества участников МФО и роста спроса на микрозаймы размер портфеля МФО (сумма задолженности по основному долгу по выдан- 
Таблица 3. Количество договоров микрозайма МФО, заключенных за отчетный квартал

\begin{tabular}{|c|c|c|c|c|c|c|}
\hline № ח/ח & Наименование показателя & Год & 1 квартал & 2 квартал & 3 квартал & 4 квартал \\
\hline \multirow{2}{*}{1} & Всего, тыс. ед. & 2017 & 5693,24 & 5660,41 & 5330,0 & 6815,19 \\
\hline & В Т.ч.: & 2018 & 6426,57 & 7287,16 & 7531,45 & н/д \\
\hline \multirow{2}{*}{1.1} & \multirow{2}{*}{ индивидуальные предприниматели } & 2017 & 3,52 & 3,37 & 5,11 & 2,36 \\
\hline & & 2018 & 3,06 & 3,25 & 3,52 & $\mathrm{H} / д$ \\
\hline \multirow{2}{*}{1.2} & \multirow{2}{*}{ юридические лица } & 2017 & 3,52 & 8,18 & 6,12 & 2,86 \\
\hline & & 2018 & 3,74 & 4,81 & 3,94 & н/д \\
\hline \multirow{2}{*}{1.3} & \multirow{2}{*}{ физические лица } & 2017 & 5686,2 & 5648,86 & 5318,77 & 6809,97 \\
\hline & & 2018 & 6419,77 & 7279,10 & 7523,99 & н/д \\
\hline \multirow{2}{*}{2} & \multirow{2}{*}{ онлайн микрозаймы, ед. } & 2017 & $\mathrm{H} / д$ & $\mathrm{H} / д$ & $\mathrm{H} /$ д & $\mathrm{H} /$ д \\
\hline & & 2018 & 2562,91 & 3009,53 & 3186,57 & н/д \\
\hline
\end{tabular}

ным микрозаймам) постоянно растет [5]. Так, по итогам III квартала 2018 г. профильные активы МФО увеличились на $11,2 \%$, прирост за год составил $32,9 \%$. В результате портфель микрозаймов МФО достиг 148,6 млрд руб., при этом 92,6 \% квартального прироста совокупного портфеля пришлось на портфель физических лиц, по 3,7\% - на портфели индивидуальных предпринимателей и юридических лиц (таблица 4).

Таблица 4. Профильные активы (сумма задолженности по основному долгу по выданным микрозаймам) на конец отчетного периода, млн руб.

\begin{tabular}{|c|c|c|c|c|c|c|}
\hline № ח/ח & Наименование показателя & Год & 1 квартал & 2 квартал & 3 квартал & 4 квартал \\
\hline \multirow{2}{*}{1} & \multirow{2}{*}{ Всего, в т.ч.: } & 2017 & 96399,3 & 104106,1 & 111793,40 & 112759,1 \\
\hline & & 2018 & 119397,3 & 133673,9 & 148585,9 & $\mathrm{H} /$ Д \\
\hline \multirow{2}{*}{1.1} & \multirow{2}{*}{ Индивидуальные предприниматели } & 2017 & 11878,1 & 10806,4 & 12478,8 & 12570,4 \\
\hline & & 2018 & 12943,6 & 14162,50 & 14707,2 & н/д \\
\hline \multirow{2}{*}{1.2} & \multirow{2}{*}{ Юридические лица } & 2017 & 10267,2 & 10040,5 & 10855,10 & 11408,9 \\
\hline & & 2018 & 11298,7 & 12371,50 & 12926,7 & $\mathrm{H} /$ д \\
\hline \multirow{2}{*}{1.3} & \multirow{2}{*}{ Физические лица } & 2017 & 74254,0 & 83259,2 & 88459,5 & 88779,7 \\
\hline & & 2018 & 95155,0 & 107139,9 & 120925,0 & н/д \\
\hline \multirow{2}{*}{2} & \multirow{2}{*}{ Онлайн микрозаймы } & 2017 & H/д & $\mathrm{H} /$ д & н/д & 15226,4 \\
\hline & & 2018 & 18338,8 & 21750,1 & 26761,1 & $\mathrm{H} / д$ \\
\hline
\end{tabular}

Структура совокупного портфеля микрозаймов в разрезе основных категорий потребителей микрофинансовых услуг практически не изменилась: $~ 90 \%$ составляют микро- займы, выданные физическим лицам, $4 \%$ - микрозаймы индивидуальным предпринимателям и $\sim 6 \%$ - микрозаймы юридическим лицам (таблица 5).

Таблица 5. Структура совокупного портфеля микрозаймов в разрезе основных категорий потребителей микрофинансовых услуг

\begin{tabular}{|c|c|c|c|c|c|c|}
\hline № П/ח & Наименование показателя & Год & 1 квартал & 2 квартал & 3 квартал & 4 квартал \\
\hline \multirow{2}{*}{1} & \multirow{2}{*}{ Индивидуальные предприниматели } & 2017 & 4,09 & 4,0 & 4,58 & 4,36 \\
\hline & & 2018 & 3,56 & 3,75 & 3,77 & $\mathrm{H} / \mathrm{д}$ \\
\hline \multirow{2}{*}{2} & \multirow{2}{*}{ Юридические лица } & 2017 & 4,62 & 5,95 & 6,56 & 5,92 \\
\hline & & 2018 & 4,44 & 5,4 & 5,24 & $\mathrm{H} / д$ \\
\hline \multirow{2}{*}{3} & \multirow{2}{*}{ Физические лица } & 2017 & 91,29 & 90,05 & 88,85 & 89,71 \\
\hline & & 2018 & 92,0 & 90,85 & 90,99 & $\mathrm{H} / д$ \\
\hline
\end{tabular}


При этом доля микрозаймов «До зарплаты» (то есть выданных в сумме не более 30 тыс. руб. на срок, не превышающий 30 дней) в совокупном портфеле микрозаймов физических лиц в анализируемых периодах варьирует на уровне 50 \%. (таблица 6).

Средняя сумма микрозаймов, выданных микрофинансовыми организациями, варьирует в пределах 10-11 тыс. руб. (таблица 7).
По сведениям Ассоциации российских банков (далее - АРБ) и Национального рейтингового агентства (далее - НРА) сумма задолженности по выданным займам на конец 3 квартала 2018 г. у микрофинансовых организаций по итогам 3 квартала 2018 г. составила $\sim 45,2$ млрд руб., продемонстрировав рост на $12 \%$ за предыдущие 3 мес. (значение на конец 2 квартала 2018 г., по аналогичному списку компаний — 40,4 млрд руб.).

Таблица 6. Характеристика выдачи МФО микрозаймов «До зарплаты»*

\begin{tabular}{|c|c|c|c|c|c|c|}
\hline № П/П & Наименование показателя & Год & 1 квартал & 2 квартал & 3 квартал & 4 квартал \\
\hline \multirow{2}{*}{1} & \multirow{2}{*}{$\begin{array}{l}\text { Совокупная сумма выданных микрозаймов «До } \\
\text { зарплаты», млн руб. }\end{array}$} & 2017 & $\mathrm{H} / д$ & $\mathrm{H} / д$ & $\mathrm{H} / Д$ & 119920,3 \\
\hline & & 2018 & 32619,0 & 65570,6 & 104608,3 & $\mathrm{H} / д$ \\
\hline \multirow{2}{*}{2} & \multirow{2}{*}{$\begin{array}{l}\text { Доля в совокупном портфеле потребительских } \\
\text { микрозаймов, \% }\end{array}$} & 2017 & $\mathrm{H} /$ д & $\mathrm{H} /$ д & $\mathrm{H} / д$ & 52,2 \\
\hline & & 2018 & 50,58 & 47,7 & 48,47 & $\mathrm{H} / д$ \\
\hline \multirow{2}{*}{3} & \multirow{2}{*}{$\begin{array}{l}\text { Количество договоров, заключенных в отчет- } \\
\text { ном периоде, тыс. ед. }\end{array}$} & 2017 & $\mathrm{H} /$ Д & Н/Д & $\mathrm{H} /$ д & 18193,76 \\
\hline & & 2018 & 4705,54 & 9913,71 & 15192,65 & $\mathrm{H} /$ д \\
\hline
\end{tabular}

Таблица 7. Средняя сумма микрозаймов, выданных МФО, тыс. руб.

\begin{tabular}{|c|c|c|c|c|c|c|}
\hline № п/п & Наименование показателя & Год & 1 квартал & 2 квартал & 3 квартал & 4 квартал \\
\hline \multirow{2}{*}{1} & \multirow{2}{*}{ Средняя сумма выданных микрозаймов } & 2017 & 9,9 & 11,4 & 11 & 11,2 \\
\hline & & 2018 & 10,9 & 11,1 & 11,4 & $\mathrm{H} /$ д \\
\hline \multirow{2}{*}{1.1} & \multirow{2}{*}{ Индивидуальным предпринимателям } & 2017 & 658,4 & 750,2 & 663,9 & 1241,8 \\
\hline & & 2018 & 817 & 975 & 930,7 & н/д \\
\hline \multirow{2}{*}{1.2} & \multirow{2}{*}{ Юридическим лицам } & 2017 & 743,7 & 560,8 & 750,5 & 1181,3 \\
\hline & & 2018 & 831,6 & 1052,5 & 1079,3 & н/д \\
\hline \multirow{2}{*}{1.3} & \multirow{2}{*}{ Физическим лицам } & 2017 & 9,1 & 10,1 & 9,5 & 10,3 \\
\hline & & 2018 & 10 & 10 & 10,4 & $\mathrm{H} / д$ \\
\hline \multirow{2}{*}{2} & \multirow{2}{*}{ Онлайн микрозаймы } & 2017 & $\mathrm{H} /$ д & $\mathrm{H} /$ д & н/д & н/д \\
\hline & & 2018 & 7,7 & 7,5 & 8,1 & н/д \\
\hline
\end{tabular}

При этом практически половина всех действующих заемщиков имеет доход, не превышающий 30 тыс. руб., 20 \% - до 40 тыс. руб. Наибольший годовой прирост (45\%) наблюдается в категории заемщиков с доходами свыше 40 тыс. руб. Количество клиентов с доходом «до 60 тыс. руб.» за год выросло на $22 \%$, «до 80 тыс. руб.» — на $50 \%$, «до 100 тыс. руб.» - $54 \%$, «свыше 100 тыс. руб.» — на $168 \%$.

Анализируя заемщиков микрофинансовых организаций с доходами выше среднего уровня, можно констатировать следующее:

1) более $40 \%$ заемщиков имеют испорченную кредитную историю;
2) $10 \%$ имеют действующую просроченную задолженность;

3) $21 \%$ по различным причинам (непостоянное место работы, отсутствие справки о доходах, отсутствие филиала банка в населенном пункте) сразу обращаются в микрофинансовые организации, минуя банковский сектор;

4) $12 \%$ заемщиков обратились в микрофинансовые организации по причине отказа в получении кредита в банке в связи с отсутствием кредитной истории;

5) $10 \%$ имеют уже несколько кредитов и в силу высокой долговой нагрузки банки их не кредитуют [6]. 
Вместе с тем, следует отметить, что те, кто ранее имел испорченную кредитную историю, начинают думать над ее исправлением - по предварительным оценкам, таких клиентов в портфелях МФО порядка 5 \%.

Таким образом, современный этап развития рынка микрофинансовых услуг характеризуется рядом положительных тенденций и социально-экономических результатов своей деятельности. Однако следует отметить, что в последнее время все чаще ведутся негативные дискуссии о микрофинансовой деятельности в России [7]. Тем не менее, дальнейшее развитие и совершенствование деятельности микрофинансовых институтов обусловлено, прежде всего, необходимостью решения существующих проблем [8].

\section{Выводы}

Теоретико-методологическое исследование рассматриваемой проблематики позволило определить и систематизировать наиболее актуальные проблемы функционирования системы микрофинансирования, решение которых позволит вывести рынок микрофинансовых услуг на качественно новый уровень своего развития.

Так, к числу факторов, сдерживающих эффективное развитие рынка микрофинансовых услуг, относятся:

— низкий уровень финансовой грамотности потребителей микрофинансовых услуг;

- отсутствие системы обязательного страхования займов;

- отсутствие залоговой базы у микрофинансовых организаций;

- высокие процентные ставки размещения займов, зачастую обусловленные отсутствием долгосрочных и дешевых источников фондирования;

\section{Список литературы}

1. Базюк Н. Микрофинансовые организации России: микрозаймы и инвестиции // Социально-экономические науки и гуманитарные исследования. 2016. № 13. С. 7-11.

2. Григорян С.А. Проблемы и перспективы микрофинансирования в России //
- недостаточный объем финансовых ресурсов, находящихся в распоряжении микрофинансовых организаций, не способных удовлетворить потенциальный спрос на микрофинансовые услуги;

- неразвитость системы управления рисками;

- присутствие «теневого сектора» на рынке микрофинансовых услуг;

- недостаточная проработанность действующего законодательства, регламентирующего деятельность рынка микрофинансовых услуг;

- отсутствие унифицированных форм отчетности микрофинансовых организаций, позволяющих получить объективную оценку их деятельности и отвечающих требованиям мировых стандартов;

- отсутствие единообразных показателей, характеризующих финансовую устойчивость микрофинансовых организаций;

- практическое отсутствие государственной поддержки рынка микрофинансовых услуг;

- отсутствие единых стандартов реструктуризации и рефинансирования займов;

- отсутствие утвержденных рейтинговых оценок микрофинансовых организаций;

- отсутствие механизма выявления и пресечения злоупотреблений в сфере микрофинансовой деятельности.

Таким образом, подводя итоги рассмотрению текущего состояния и факторов, сдерживающих развитие рынка микрофинансовых услуг в России, отметим, что перспективы развития микрофинансовых институтов будут напрямую зависеть от эффективности решения выше обозначенных проблем.

Вестник научных конференций. 2016. № 3-4 (7). C. 31-34.

3. Захарова О.В. Проблемы функционирования и регулирования институтов микрофинансирования в России // Проблемы экономики, финансов и управления производством: сб. науч. тр. вузов России. 2017. № 40. C. 14-21. 
4. Зиганшина Е.А., Пуговкина Ю.А., Самородова А.С., Барбарская М.Н. Основные аспекты функционирования рынка микрофинансирования на территории Российской Федерации // Наука и образование: новое время. 2017. № 3. С. 34-40.

5. НБКИ: в 1 квартале 2018 года рост портфеля займов МФО составил $10 \%$. URL: https://www.nbki.ru/press/pressrelease/ ?id=21700 (дата обращения: 12.05.2019).

6. Обзор ключевых показателей микрофинансовых институтов // https:/www.cbr.ru/ analytics/analytics_nfo/ (дата обращения: 12.05.2019).

7. Семенова К.С. Микрофинансирование в России и за рубежом: сравнительный анализ // Современные научные исследования и разработки. 2017. Т. 2. № 1 (9). С. 458-460.

8. Шиликова В. Роль микрофинансовых организаций в развитии финансового рынка России // Образование и наука без границ: социально-гуманитарные науки. 2017. № 7. C. 118-122.

\section{References}

1. Bazyuk N. Mikrofinansovye organizatsii Rossii: mikrozaimy i investitsii [Microfinance Organizations of Russia: Microloans and Investments]. Sotsial'no-ekonomicheskie nauki $i$ gumanitarnye issledovaniya - Social and Economic Sciences and Humanitarian Studies, 2016, No. 13, pp. 7-11. [in Russian].

2. Grigoryan S.A. Problemy i perspektivy mikrofinansirovaniya $\mathrm{v}$ Rossii [Problems and Prospects of Microfinance in Russia]. Vestnik nauchnykh konferentsii - Bulletin of Scientific Conferences, 2016, No. 3-4 (7), pp. 31-34. [in Russian].

3. Zakharova O.V. Problemy funktsionirovaniya i regulirovaniya institutov mikrofinansirovaniya v Rossii [Problems of Functioning and Regulation of Microfinance Institutions in Russia]. Sbornik nauchnykh trudov vuzov Rossii
«Problemy ekonomiki, finansov i upravleniya proizvodstvom» [Collection of Scientific Papers of Russian Universities «Problems of Economics, Finance and Production Management»]. Ivanovo, 2017. No. 40, pp. 14-21. [in Russian]. 4. Ziganshina E.A., Pugovkina Yu.A., Samorodova A.S., Barbarskaya M.N. Osnovnye aspekty funktsionirovaniya rynka mikrofinansirovaniya na territorii Rossiiskoi Federatsii [The Main Aspects of the Microfinance Market in the Territory of the Russian Federation]. Nauka i obrazovanie: novoe vremya - Science and Education: New Times, 2017, No. 3, pp. 34-40. [in Russian].

5. NBKI: $v 1$ kvartale 2018 goda rost portfelya zaimov MFO sostavil $10 \%$ [NBCH: in the $1^{\text {st }}$ Quarter of 2018, the Growth of the MFI Loan Portfolio Amounted to $10 \%]$. Available at: https://www.nbki.ru/press/pressrelease/ ?id=21700 (accessed 12.05.2019). [in Russian].

6. Obzor klyuchevykh pokazatelei mikrofinansovykh institutov [Review of Key Indicators of Microfinance Institutions]. Available at: https://www.cbr.ru/analytics/analytics_nfo (accessed 12.05.2019). [in Russian].

7. Semenova K.S. Mikrofinansirovanie v Rossii i za rubezhom: sravnitel'nyi analiz [Microfinance in Russia and Abroad: a Comparative Analysis]. Sovremennye nauchnye issledovaniya i razrabotki - Modern Scientific Research and Development, 2017, Vol. 2, No. 1 (9), pp. 458-460. [in Russian].

8. Shilikova V. Rol' mikrofinansovykh organizatsii v razvitii finansovogo rynka Rossii [The role of Microfinance Organizations in the Development of the Financial Market of Russia]. Sbornik nauchnykh trudov "Obrazovanie $i$ nauka bez granits: sotsial'no-gumanitarnye nauki» [Collection of Scientific Papers «Education and Science without Borders: Social and Humanitarian Sciences»]. Orel, 2017. No. 7. pp. 118-122. [in Russian]. 